\title{
Characterization of Differentially Methylated Regions in 3 Bovine Imprinted Genes: A Model for Studying Human Germ-Cell and Embryo Development
}

\author{
T. Hansmann ${ }^{\text {a }} \quad$ J. Heinzmann ${ }^{\text {b }} \quad$ C. Wrenzyckic ${ }^{c}$ U. Zechner ${ }^{d} \quad$ H. Niemann ${ }^{\text {b }}$ \\ T. Haafa \\ a Institute of Human Genetics, Biocenter, University of Würzburg, Würzburg, ' Institute of Farm Animal Genetics, \\ Friedrich Loeffler Institute, Mariensee, ${ }^{c}$ Clinic for Cattle, University of Veterinary Medicine Hannover, Hannover, \\ and ${ }^{d}$ Institute of Human Genetics, Mainz University Medical Center, Mainz, Germany
}

\section{Key Words}

Bovine - Differentially methylated region - IGF2-H19 • Imprinting control region

\begin{abstract}
Correct imprinting is crucial for normal fetal and placental development in mammals. Experimental evidence in animal models and epidemiological studies in humans suggest that assisted reproductive technologies (ARTs) can interfere with imprinted gene regulation in gametogenesis and early embryogenesis. Bos taurus is an agriculturally important species in which ARTs are commonly employed. Because this species exhibits a similar preimplantation development and gestation length as humans, it is increasingly being used as a model for human germ-cell and embryo development. However, in contrast to humans and mice, there is relatively little information on bovine imprinted genes. Here, we characterized the bovine intergenic IGF2-H19 imprinting control region (ICR) spanning approximately $3 \mathrm{~kb}$. We identified a 300-bp differentially methylated region (DMR) approximately $6 \mathrm{~kb}$ upstream of the $\mathrm{H} 19$ promoter, containing a $\mathrm{CpG}$ island with CTCF-binding site and high sequence similarity with the
\end{abstract}

human intergenic ICR. Additional differentially methylated CpG islands lie $-6 \mathrm{~kb}$ to $-3 \mathrm{~kb}$ upstream of the promoter, however these are less conserved. Both classical bisulfite sequencing and bisulfite pyrosequencing demonstrated complete methylation of the IGF2-H19 ICR in sperm, complete demethylation in parthenogenetic embryos having only the female genome, and differential methylation in placental and somatic tissues. In addition, we established pyrosequencing assays for the previously reported bovine SNRPN and PEG3 DMRs. The observed methylation patterns were consistent with genomic imprinting in all analyzed tissues/ cell types. The identified IGF2-H19 ICR and the developed quantitative methylation assays may prove useful for further studies on the relationship between ARTs and imprinting defects in the bovine model.

Copyright $\odot 2010$ S. Karger AG, Basel

Genomic imprinting is the epigenetic mark of a subset of genes that results in silencing of one of the 2 parental alleles. Parental allele-specific methylation of cis-regulatory elements (called differentially methylated regions; DMRs) during gametogenesis controls the preferential or

\section{KARGER}

Fax +4161306 1234

E-Mail karger@karger.ch

www.karger.com
(C) 2010 S. Karger AG, Basel

$1424-8581 / 11 / 1324-0239 \$ 38.00 / 0$

Accessible online at:

www.karger.com/cgr
T. Haaf

Institute of Human Genetics

Biocenter, Julius Maximilians University

DE-97074 Würzburg (Germany)

Tel. +49 93131 88738, Fax +4993131 84069, E-Mail thomas.haaf@uni-wuerzburg.de 
exclusive expression of the non-imprinted allele [Kelsey, 2007; Ideraabdullah et al., 2008]. The genomic methylation patterns in somatic cells are generally stable and maintained during cell division. However, dramatic genome-wide changes in DNA methylation occur in the male and female germ line, respectively, and shortly after fertilization [Reik and Walter, 2001; Li, 2002]. Following complete demethylation in mouse primordial germ cells ensuring an equivalent epigenetic state of both parental alleles, the germ line genomes undergo sex-specific de novo methylation including the establishment of parentspecific methylation imprints [Hajkova et al., 2002]. A second wave of genome-wide demethylation and subsequent de novo methylation occurs during mouse, bovine and human preimplatation development [Mayer et al., 2000; Dean et al., 2001; Beaujean et al., 2004]. The vast majority of male and female germ line-derived methylation patterns are erased again and somatic methylation patterns are established around the time of implantation [Reik and Walter, 2001; Haaf, 2006]. Only the differential methylation patterns of imprinted genes remain unaffected by this second wave of reprogramming, maintaining their parent-specific activity throughout further development. The majority of imprinted genes plays essential roles in mammalian development, notably in the regulation of placental, fetal and/or postnatal growth [Miozzo and Simoni, 2002; Reik et al., 2003]. To date about 80 imprinted genes are known in the mouse (http:// www.mousebook.org/catalog.php?catalog=imprinting) and other mammalian species (http://igc.otago.ac.nz/ home.html). The true number of imprinted genes among the approximately 25,000 mammalian genes remains elusive; conservative estimates are 100-200. However, highresolution expression analysis by RNA sequencing identified more than 1,000 loci with possibly preferential expression of the paternal or maternal allele in mouse brain regions [Gregg et al., 2010]. The limited number can by explained by the fact that at a functional level imprinted genes are haploid and therefore particularly vulnerable to the deleterious effects of mutations and epimutations [Jirtle and Weidmann, 2007].

Mammalian imprinted genes are generally organized in clusters which contain both paternally and maternally imprinted genes. Differentially methylated control elements are shared by multiple imprinted genes of a specific cluster [Edwards and Ferguson-Smith, 2007]. For example, the oppositely imprinted insulin-like growth factor 2 (IGF2) and $\mathrm{H} 19$ genes on human chromosome 11 p15.5 and distal mouse chromosome 7, respectively, are regulated by an intergenic imprinting control region
(ICR), which is called imprinting center 1 (IC1) in humans and differentially methylated domain (DMD) in mouse. The IGF2-H19 ICR is methylated in the male germ line. The unmethylated ICR on the maternal chromosome can bind the enhancer blocking CTCF protein (CCCTC-binding factor) at CCCTC recognition sites. CTCF prevents activation of promoters by blocking the interaction with enhancers. Thus, the IGF2-H19 ICR acts as a methylation-sensitive insulator between the differentially methylated promoters of IGF2 and their endodermspecific enhancers downstream of H19 [Bell and Felsenfeld, 2000; Engel et al., 2006]. The paternally expressed IGF2 is an important growth factor for tissue differentiation, fetal and placental development. The function of the untranslated H19 mRNA is still unclear. It may act as a tumor suppressor or as an oncogene in various cancers [Ideraabdullah et al., 2008]. Methylation abnormalities of the intergenic ICR lead to dysregulation of IGF2-H19 imprinting. In humans, ICR hypomethylation is associated with intrauterine growth retardation (Silver-Russell-Syndrome) [Gicquel et al., 2005], whereas hypermethylation leads to fetal overgrowth (Beckwith-Wiedemann syndrome) [Cooper et al., 2005]. The DMR in the promoter/ exon 1 of the small nuclear ribonucleoprotein polypeptide $\mathrm{N}(S N R P N)$ gene is methylated in the maternal germ line and regulates imprinting of genes in the Prader-Willi and Angelman syndrome region [Horsthemke and Buiting, 2006]. The paternally expressed gene 3 (PEG3) is also endowed with a maternally methylated DMR; it is expressed in the embryo and placenta and may induce apoptosis [Huang and Kim, 2009].

Because of legal and ethical restrictions, assisted reproductive technologies (ART)-induced epigenetic changes are difficult to study in human germ cells and embryos. In many aspects, bovine germ-cell and preimplantation development appear to be a better model for humans than the mouse [Ménézo and Hérubel, 2002; Wrenzycki et al., 2005]. Both bovine and human are uniparous species. They have a similar cell division rate of preimplantation development which is slower than in murine embryos and a gestation period of 9 months compared to 21 days for the mouse. In Bos taurus (BTA) and humans, the final stages of oocyte maturation are subject to subtle regulation and a minimum follicle size is necessary to complete maturation in vitro. Bovine and human preimplantation embryos are also similar with regard to biochemical and intrinsic paternal and maternal regulatory processes. In vitro production methods for bovine embryos are well advanced. Bovine blastocysts developing in vivo are readily obtained non-surgically by uterine 
flushing. However, the use of the bovine model is hampered by our limited knowledge about bovine imprinted genes which play a crucial role in fetal and placental development. The goal of this study was to identify the intergenic IGF2-H19 ICR in bovine material, which has been well characterized in humans and mouse and functions as a primary control element of IGF2-H19 imprinting. Up to now only a DMR in the last exon of the bovine IGF2 gene has been characterized in some detail [Gebert et al., 2006; 2009]. Another DMR in the upstream region of bovine $H 19$ has been reported, however with the information given in the paper [Curchoe et al., 2009], we were not able to localize the amplicon in the bovine intergenic IGF2-H19 region of interest. For future studies on the possible effects of in vitro manipulations of bovine germ cells and embryos on genomic imprinting, we established high-throughput pyrosequencing assays for the quantitative methylation analysis of 3 representative bovine DMRs, IGF2-H19, SNRPN and PEG3.

\section{Material and Methods}

\section{Sequence Analysis}

Sequences of the human (Homo sapiens, HSA) and mouse (Mus musculus, MMU) IGF2-H19 region were retrieved from the NCBI database (http://www.ncbi.nlm.nih.gov; human contig NT009237.18 and locus AF125183 on HSA11:2,020,592-2,022,331 bp, NCBI build 37.1; mouse contig NT039437.7 on MMU7: 149,766,048-149,768,048 bp; NCBI build 37.1). A BLAST search [Altschul et al., 1990] was carried out with the human IGF2-H19 IC1 (AF125183: 6,841-8,521 bp) against the B. taurus genome (version Btau 4.0 of August 5, 2008). CpG islands were predicted using the default settings of the MethPrimer program [Li and Dahiyam, 2002]. Sequence conservation between species was analyzed with multiVISTA (http://www-gsd.lbl.gov/vista/) and LAGAN [Brudno et al., 2003]. CTCF-binding sites were predicted with CTCFBSDB [Bao et al., 2008].

Tissue Samples

Parthenogenetic embryos were produced as described previously [Wrenzycki et al., 2002]. Briefly, oocytes were in vitro matured (IVM) in TCM199 medium (Sigma-Aldrich, Munich, Germany), at pH 7.4 supplemented with $0.2 \mathrm{~mm} \mathrm{Na}$-pyruvate, $25 \mathrm{~mm}$ $\mathrm{NaHCO}_{3}, 1 \mathrm{mg} / \mathrm{ml}$ BSA-FAF (Sigma-Aldrich), $10 \mathrm{IU} / \mathrm{ml}$ of pregnant mare serum gonadotropin and $5 \mathrm{IU} / \mathrm{ml}$ of human chorionic gonadotropin (Intervet, Unterschleißheim, Germany), at $39^{\circ} \mathrm{C}$ in $5 \% \mathrm{CO}_{2}$ in air. After $22-25 \mathrm{~h}$, adhering cumulus cells were removed from oocytes by incubation with $0.1 \%$ hyaluronidase (Sigma-Aldrich) in Ca- and $\mathrm{Mg}$-free PBS for 2 min at $39^{\circ} \mathrm{C}$. Subsequently, oocytes were activated for $5 \mathrm{~min}$ with $5 \mu \mathrm{M}$ ionomycin (Sigma-Aldrich) in TCM199 and then incubated for $3.5 \mathrm{~h}$ at $37^{\circ} \mathrm{C}$ with 6-dimethylaminopurin (Sigma-Aldrich). The resulting embryos were cultured in modified synthetic oviduct fluid (SOFaa) supplemented with $4 \mathrm{mg} / \mathrm{ml} \mathrm{BSA-FAF}$ [Wrenzycki et al, 2001].
Placental tissue was obtained after natural birth of a HolsteinFriesian calf conceived by artificial insemination. The sperm sample was derived from a bull commonly used for artificial insemination. Visceral tissues (heart, kidney and liver) of different cows were obtained from a local slaughterhouse. Samples were stored at $-80^{\circ} \mathrm{C}$ until further use.

\section{DNA Isolation and Bisulfite Treatment}

The DNeasy Blood and Tissue Kit (Qiagen, Hilden Germany) was used for genomic DNA preparation. Sperm samples were first purified with Pure Sperm 40/80 (Nidacon, Mölndal, Sweden) to remove contaminating somatic and abnormal spermatogenic cells. Pure sperm samples were treated with $100 \mathrm{mM}$ TrisCl, 10 mM EDTA, $500 \mathrm{mM} \mathrm{NaCl}, 1 \%$ SDS, and $2 \% \beta$-mercaptoethanol and then incubated for $2 \mathrm{~h}$ at $56^{\circ} \mathrm{C}$ with proteinase $\mathrm{K}$. Bisulfite conversion of sperm, placenta, heart, kidney, and liver DNA was performed with the EpiTect Bisulfite Kit (Qiagen). Bisulfite conversion of about 100 cells from parthenogenetic embryos was carried out with the EZ DNA Methylation-Direct Kit (Zymo Research, Freiburg, Germany) which is particularly suitable for low amounts of DNA.

\section{Bisulfite Plasmid Sequencing}

Polymerase chain reaction (PCR) of bisulfite-treated DNA was performed with FastStart Taq DNA Polymerase (Roche Diagnostics, Mannheim, Germany). The reaction mixture consisted of $2.5 \mu \mathrm{l} 10 \times$ PCR buffer, $20 \mathrm{mM} \mathrm{MgCl}_{2}, 0.5 \mu \mathrm{l} 10 \mathrm{mM}$ dNTP mix, $1.0 \mu \mathrm{l}(10 \mathrm{pmol})$ of each forward and reverse primer, $0.2 \mu \mathrm{l}(1 \mathrm{U})$ Taq, $18.8 \mu$ l PCR-grade water and $1 \mu \mathrm{l}(\sim 100 \mathrm{ng})$ template DNA. PCR amplifications were carried out with an initial denaturation step at $95^{\circ} \mathrm{C}$ for $4 \mathrm{~min}, 30-35$ cycles of $95^{\circ} \mathrm{C}$ for $30 \mathrm{~s}$, primer-specific annealing temperature for $30 \mathrm{~s}, 72^{\circ} \mathrm{C}$ for $45 \mathrm{~s}$, and a final extension step at $72^{\circ} \mathrm{C}$ for $7 \mathrm{~min}$.

A semi-nested PCR assay was designed for classical bisulfite sequencing of the bovine IGF2-H19 ICR, using outer forward primer 5'-GATAGGAGATTAGGTTTAGAGGG-3', inner forward primer 5'-TGATTTTTTAGTTTTATTGTTTTTG-3', and reverse (outer and inner) primer 5'-ATAAAAATCCCTCAATATCCC-3'. The 386-bp first-round amplicon is located on BTA chromosome $29(51,358,389-51,358,774 \mathrm{bp})$ in contig NW $001494547.2(3,718,453-3,718,838 \mathrm{bp})$. The 300 -bp second-round amplicon contains $23 \mathrm{CpG}$ sites. Both first- and second-round PCR were performed with 30 cyles and an annealing temperature of $55^{\circ} \mathrm{C}$. PCR products were cloned into pGEM-T vector using T4-DNA ligase (Promega, Madison, Wisc., USA). Plasmid DNA of individual clones was isolated with the NucleoSpin Plasmid Extraction Kit (Macherey-Nagel, Düren, Germany). Clones containing inserts of the right size were sequenced using dye terminator cycle sequencing with M13 primers and the CEQ DTCS Quick Start Kit (Beckman Coulter, Krefeld, Germany). Sequencing products were separated on a Beckman Coulter CEQ 8000 Genetic Analysis System. SCF files were analyzed by visual inspection using Chromas Lite (http://www.technelysium.com.au/ chromas_lite.html) and BioEdit software [Hall, 1999]. At least 10 clones were sequenced for each tissue.

\section{Bisulfite Pyrosequencing}

Bisulfite pyrosequencing is a highly accurate high-throughput technique for quantitative methylation analysis. Three pyrosequencing assays were designed to quantify the methylation level 
of different $\mathrm{CpG}$ islands in the 3.1-kb putative intergenic IGF2H19 ICR. The first assay analyzes 9 CpG sites at CTCF-binding site 1 in the cloned amplicon. First-round PCR was performed with the inner forward and reverse primers for plasmid sequencing, described above. Second-round PCR (35 cycles with an annealing temperature of $57^{\circ} \mathrm{C}$ ) was performed with inner primer 5'-AGAGGTTGTGGGTGTGGAGATA-3' and 5'-biotinylated reverse primer $5^{\prime}$-TCСТCTCССАССТТСААСАA-3'. The resulting 230-bp amplicon was sequenced with primer 5'-GGGTTTGTATATTATAGGAT-3'. The other 2 assays target $5 \mathrm{CpG}$ sites each at CTCF-binding sites 4 and 7, respectively. For site 4, first-round PCR was performed with outer forward primer 5'-TTTTAAAATAGGGTTGTGTGGTTGT-3' and outer reverse primer 5'-CCAAACATAAAAATCCCTCAATATC-3' (BTA29: 51,359,843-51,360,127 bp; NW 001494547.2: 3,719,907-3,720,191 bp). Biotinylated inner forward primer $5^{\prime}$-AAAATAGGGTTGTGTGGTT-3' and inner reverse primer $5^{\prime}$-ACCACCTTAATAATAATACATAAACCTAC-3' amplified an 85-bp fragment that was sequenced with primer 5'-AATAATAATACATAAACCTACACT-3'. For CTCF-binding site 7, outer forward primer 5'-ATTTTAGATAGGGTTGAGAGGTTGT-3' and reverse primer 5'-CCAAACATAAAAATCCCTCATTATC-3' (BTA29: 51,361,210-51,361,503 bp; NW 001494547.2: 3,721,274-3,721,567 bp) were used for first-round PCR, and inner forward primer 5'-GAGGTTGTGGGTGTGGAGAT-3' and biotinylated reverse primer 5'-ATAACTTAAACAAATATCCCATCCCC-3' for second-round PCR. The resulting 187-bp amplicon was sequenced with primer 5'-GTGGGTGTGGAGATA-3'. First-round PCR was performed with 30 cycles and an annealing temperature of $58^{\circ} \mathrm{C}$; second-round PCR with 30 cycles and an annealing temperature of $56^{\circ} \mathrm{C}$ for CTCF-binding site 4 and $58^{\circ} \mathrm{C}$ for site 7 , respectively.

For 2 previously characterized bovine imprinted genes, SNRPN [Lucifero et al., 2006] and PEG3 [Liu et al., 2008], pyrosequencing primers were designed in $\mathrm{CpG}$ islands of the reported DMRs. Methylation of $2 \mathrm{CpG}$ sites was quantified in SNRPN and of 3 sites in PEG3. First-round PCR of bovine SNRPN was performed with outer forward primer 5'-GGGTGGGGTAGATATTATTTT-3' and reverse primer 5'-CCCAAATCCCCAATAAAT-3'. The 356-bp first-round amplicon is located on BTA chromosome 21 (NW 001501801.1: 23,926-24,281 bp). The inner forward primer 5'-GGTTTTTTTGTTTGAGAGAG-3' and 5'-biotinylated reverse primer yielded a second-round PCR product of $334 \mathrm{bp}$, which was sequenced with primer 5'-GGTTTTTTTGTTTGAGAGA- $3^{\prime}$. Both first- and second-round PCR were performed with 32 cyles and an annealing temperature of $55^{\circ} \mathrm{C}$. For bovine PEG3, outer primers $5^{\prime}$-GATATGTTTATTTTTGGTTGTTGG-3' (forward) and 5'-ACCCTAATCCCAAACTCCAACTAACC-3' (reverse) were used for first-round PCR (30 cycles with an annealing temperature of $59^{\circ} \mathrm{C}$ ), generating an amplicon of 280-bp length (BTA18: 64,374,680-64,374,959 bp; NW 001493639.2: 537,812-538,091 bp). 5'-Biotinylated inner forward primer 5'-GTGTGGGGGTATTAGAGTTTGT-3' and inner reverse primer 5'-ACCCTAATCCCAAACTCCA-3' were used for second round PCR ( 32 cycles with an annealing temperature of $60^{\circ} \mathrm{C}$ ). The resulting 235 -bp amplicon was sequenced with primer 5'-CCCACTAACCAAAAT-3'.

Bisulfite pyrosequencing was performed on a PSQ 96MA Pyrosequencing System (Biotage, Uppsala, Sweden) with the PyroGold SQA reagent kit (Biotage) [Tost et al., 2003]. Pyro Q-CpG software (Biotage) was used for data analysis.

\section{Results}

Identification of the Bovine Intergenic IGF2-H19 ICR

In humans, the intergenic IGF2-H19 IC1 comprises a series of 400-bp repeats, called repeat unit 1 . It starts about $-2 \mathrm{~kb}$ upstream of the $\mathrm{H} 19$ transcription start site and extends further upstream [Frevel et al., 1999]. Sequence conservation of the intergenic IGF2-H19 ICR is relatively low (51\% between human and mouse, $54 \%$ between human and cow, and 50\% between mouse and cow), which renders in silico prediction of the bovine DMR difficult. A BLAST search with the human IC1 sequence against the bovine genome revealed several short hits in a $3.4-\mathrm{kb}$ region $(51,358,400-51,361,800 \mathrm{bp})$ between IGF2 and H19 on BTA chromosome 29 (fig. 1A, B). The online prediction tool MethPrimer identified several $\mathrm{CpG}$ islands in this region between $-6.1 \mathrm{~kb}$ and $-3 \mathrm{~kb}$ upstream of the $\mathrm{H} 19$ transcription start site (TSS) (fig. 1C). A 450-bp segment encompassing the first $2 \mathrm{CpG}$ islands (fig. 1C) displayed the highest sequence similarity in alignments with human IC1 (fig. 1D, blue circle). This segment (BTA29: 51,358,550-51,359,000) was located about $-6 \mathrm{~kb}$ upstream of the $H 19$ promoter in the most upstream segment of the 3.4-kb region. Since the human IC1 functions as an insulator by binding the enhancerblocking CTCF protein [Bell and Felsenfeld, 2000; Engel et al., 2006], we screened the 3.4-kb bovine region for the presence of CTCF-binding sites. Seven CTCF-binding sites were identified in the CTCFBS database (fig. 1D, red lines). A binding site with the consensus sequence $5^{\prime}$ GCGGCCGCGAGGCGGCAGTG-3' was detected in the first CpG island of the evolutionarily conserved 450-bp DNA segment (site 1 in fig. 1D). An orthologous site, human CTCF-binding site 6 resides in repeat $\mathrm{B} 1$ of repeat unit 1 in the human intergenic IGF2-H19 IC1, which is differentially methylated on the paternal allele [Frevel et al., 1999; Takai et al., 2001]. The sequence of this site is highly conserved between human, mouse, rat [Bell and Felsenfeld, 2000] and bovine (fig. 1D, E). The bovine CTCF-binding sites 4 and 7 (fig. 1D) share the same sequence as CTCF-binding site 1, but lie in less conserved DNA segments.

\section{Parent-Specific Methylation of the Bovine \\ IGF2-H19 ICR}

Bisulfite plasmid sequencing is the gold standard for first-time methylation analysis of a region because it allows one to look at a larger number of $\mathrm{CpG}$ sites in individual DNA molecules. We designed a semi-nested PCR assay for the putative bovine IGF2-H19 ICR. The 300- 
Fig. 1. Identification of the bovine intergenic IGF2-H19 ICR. A Schematic drawing of the bovine IGF2-H19 region. The IGF2 gene is transcribed from the paternal chromosome (blue arrow), H19 from the maternal chromosome (red arrow). B BLASTsearch results with the human IC1 sequence against the $B$. taurus genome. BLAST hits are found in a $3.4-\mathrm{kb}$ region (BTA29: 51,358,400-51,361,800 bp; version Btau 4.0), indicated by the orange box $-6.4 \mathrm{~kb}$ to $-3 \mathrm{~kb}$ upstream of the bovine H19 transcription start site. C GC percentage and distribution of $\mathrm{CpG}$ islands (indicated in light blue) in the 3.4 -kb region, orthologous to human IC1. Gray double arrows in $\mathrm{C}$ and $\mathrm{D}$ indicate the localization of the 300-bp amplicon for bisulfite sequencing. D Alignment of the $3.4-\mathrm{kb}$ bovine ICR with the human IC1 sequence (NT009237.18, AF125183). The highest sequence similarity is found in the most upstream region, encircled in blue. CTCF binding sites 1-7 are indicated by red vertical lines. E Sequence conservation between bovine CTCF-binding site 1 and human CTCF-binding site 6.

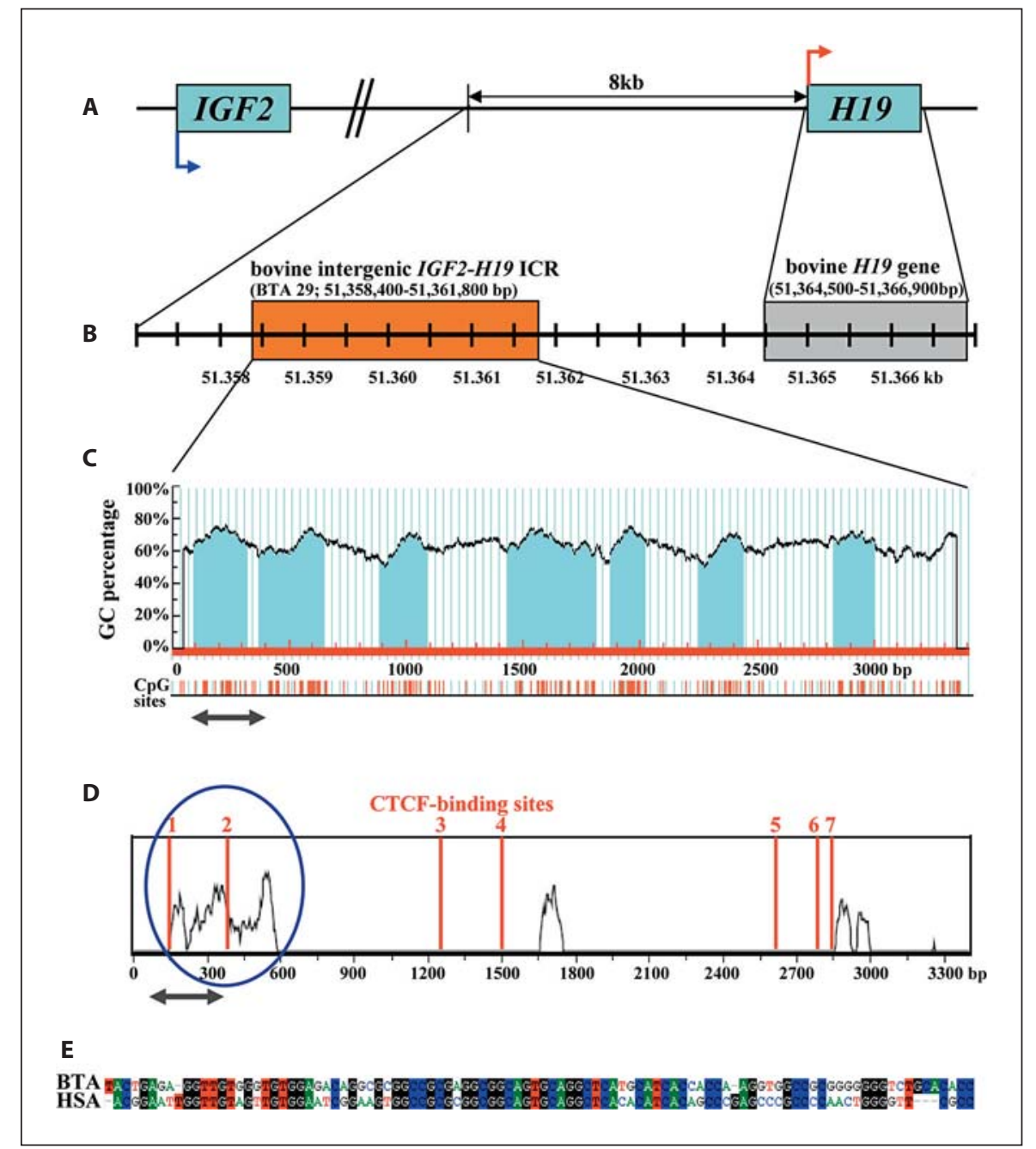

bp amplicon contains the first $\mathrm{CpG}$ island, including CTCF-binding site 1 and 23 CpG sites (fig. 1C, D, gray double arrow). As expected for the IGF2-H19 ICR, the analyzed region was completely ( $>98 \%)$ methylated in bovine sperm (fig. 2A). The few unmethylated sites in the 11 sequenced DNA molecules represent stochastic methylation errors that do not affect the imprinting status. In contrast, parthenogenetic embryos which are endowed with 2 female genomes were completely (100\%) demethylated (fig. 2B). In placenta and liver $46 \%$ and $60 \%$, respectively, of the analyzed CpGs were methylated, consistent with differential methylation of paternal and maternal alleles. In placenta (fig. 2C), 3 of 12 sequenced alleles displayed a nearly completely methylated paternal and 3 a completely demethylated maternal pattern, whereas 6 alleles showed mixed methylation patterns. This may be due to the fact that maintenance of imprints in the pla- centa depends on histone modifications rather than DNA methylation [Lewis et al., 2004] and in addition, the direct contact with environmental factors may make the placenta more susceptible to alterations in DNA methylation [Fortier et al., 2008]. In the liver (fig. 2D), 28 alleles had a paternal, 17 a maternal and only one showed an intermediate methylation pattern.

\section{Quantitative Methylation Assays for IGF2-H19, \\ SNRPN and PEG3}

Bisulfite pyrosequencing avoids the time-consuming cloning of PCR products and sequencing of 10-20 insertcontaining plasmids from each sample and, therefore, is considerably more cost-effective and faster than conventional bisulfite sequencing. However, it can only reliably measure methylation levels of a limited number of CpGs located within $30-50$ bp $3^{\prime}$ from the sequencing primer 


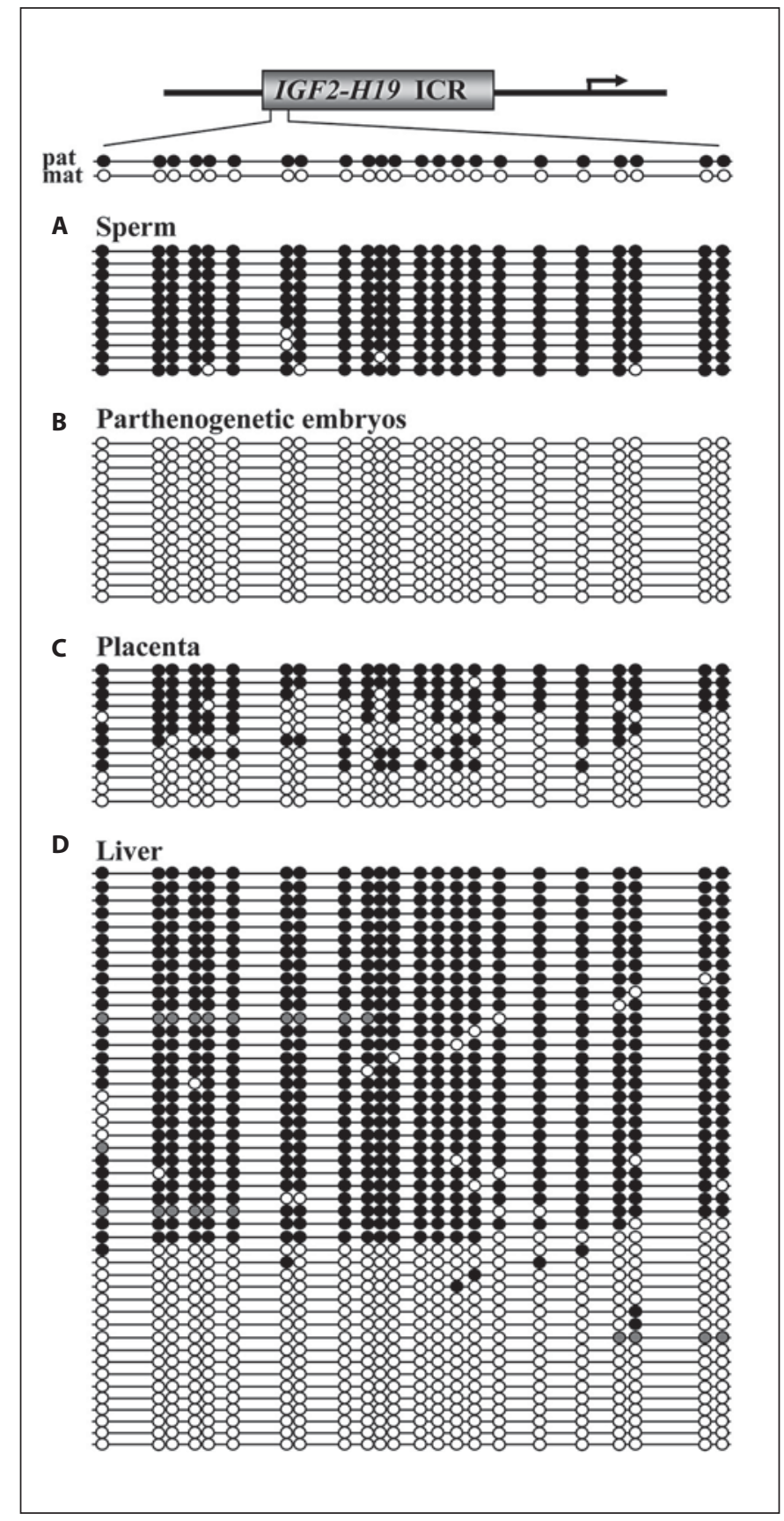

Fig. 2. Methylation status of the identified bovine intergenic IGF2-H19 ICR in sperm (A), parthenogenetic embryos (B), placenta (C), and liver (D). The analyzed region contains $23 \mathrm{CpG}$ sites. Each line represents an individual plasmid or DNA molecule in the starting sample. Filled circles indicate methylated CpG and open circles unmethylated CpG sites. Gray circles are sites that could not be analyzed because of poor sequence quality. in PCR products of 100-300 bp length. For high-throughput quantitative methylation analysis of bovine imprinted genes, we designed 3 pyrosequencing assays for the newly identified IGF2-H19 ICR and 2 assays for the previously reported SNRPN and PEG3 DMR, respectively [Lucifero et al., 2006; Liu et al., 2008]. By pyrosequencing we can quantify the methylation levels of $19 \mathrm{CpG}$ sites around CTCF-binding sites 1, 4 and 7 in the IGF2-H19 ICR, 2 sites in SNRPN, and 3 sites in PEG3. Table 1 presents the average methylation levels (of all analyzed CpGs) of the 3 bovine DMRs in sperm, parthenogenetic embryos, placenta and 3 different somatic tissues (heart, kidney and liver). The paternally imprinted IGF2-H19 DMR was hypermethlylated (88-98\%) in sperm, completely demethylated (1-2\%) in parthenogenetic embryos, and differentially methylated (45-55\%) in placenta and somatic tissues. In contrast, the maternally imprinted SNRPN and PEG3 genes were demethylated (3-4\%) in sperm, fully methylated (98-99\%) in parthenogenetic embryos, and differentially methylated (47-56\%) in placenta and somatic tissues.

\section{Discussion}

ARTs, including somatic cell nuclear transfer, in vitro fertilization (IVF) and intracytoplasmatic sperm injection (ICSI), as well as culture of embryos to a transferable stage can interfere with sensitive periods of germ-cell and embryo development in which genome-wide epigenetic reprogramming processes occur. Despite the wide-spread use of IVF and ICSI in humans, little is known about the causes of developmental failures and defects associated with ARTs. The incidence of major and minor birth defects appears to be slightly increased [Hansen et al., 2005], whereas the incidence of low birth weight is $2-3$ fold increased after IVF/ICSI [Schieve et al., 2002]. Several studies reported a 3-9 fold increased prevalence of imprinting defects that are associated with Beckwith-Wiedemann [Maher et al., 2003; Halliday et al., 2004] and Angelman syndrome [Ludwig et al., 2005] following ARTs. However, the absolute risk of conceiving an IVF/ICSI child with imprinting disorder remains low. Initially, only single case reports or small case series were published. Larger epidemiological studies in Denmark [Lidegaard et al., 2005], Sweden [Kallen et al., 2005], the United Kingdom [Bowdin et al., 2007], and the Netherlands [Doornbos et al., 2007] have questioned the increased risk for imprinting disorders in ART children. However, because human imprinting disorders are very rare and a handful of cases 
Table 1. H19, SNRPN and PEG3 DMR methylation levels in different bovine tissues, as determined by bisulfite pyrosequencing

\begin{tabular}{llllllr}
\hline \multirow{2}{*}{ Tissue/cell type } & \multicolumn{2}{l}{ Methylation level (\%) } & & \\
\cline { 2 - 4 } & \multicolumn{2}{l}{ IGF2-H19 } & & SNRPN & PEG3 \\
\cline { 2 - 4 } & CTCF 1 & CTCF 4 & CTCF 7 & & \\
\hline Sperm & 97 & 88 & 98 & 4 & 3 \\
Parthenogenetic embryos & 1 & 1 & 2 & 98 & 99 \\
Placenta & 47 & 51 & 51 & 47 & 49 \\
Heart & 47 & 55 & 51 & 56 & 50 \\
Kidney & 45 & 49 & 53 & 54 & 51 \\
Liver & 47 & 52 & 51 & 52 & 50 \\
\hline
\end{tabular}

might significantly distort the data analysis, it is not possible to exclude an association of imprinting defects and human ARTs.

Indeed, experimental evidence from animal studies is more alarming. An effect of ARTs on DNA methylation, imprinted gene expression and fetal development was first described in the mouse [Ertzeid and Storeng, 2001; Khosla et al., 2001; Shi and Haaf, 2002; Fortier et al., 2008]. However, human and rodent development differ dramatically and, therefore, it is difficult to extrapolate from the mouse to the human situation. In this light, bovine germ-cell and early embryo development is increasingly considered as a useful model for human ARTs. Following transfer of in vitro produced embryos to recipients a certain proportion of the resulting lambs or calves exhibit overgrowth abnormalities of fetus and placenta that are associated with increased pregnancy losses and an increased perinatal mortality [Farin et al., 2006]. This large offspring syndrome in ruminants, which is somewhat reminiscent of Beckwith-Wiedemann syndrome in humans, has been linked to aberrant methylation and expression of the imprinted IGF2R gene [Young et al., 2001]. In addition, cloned bovine embryos are often affected by aberrant methylation patterns either globally or in individual genes [Cezar et al., 2003; Niemann et al., 2010] and specifically in imprinted genes [Lucifero et al., 2006; Liu et al., 2008; Suzuki et al., 2009]. It is plausible to assume that normal conception, assisted reproduction and embryo cloning are all susceptible to similar dysregulation of epigenetic components. However, the frequency and severity of abnormal phenotypes increase after interfering with or bypassing essential steps of gametogenesis and/or early embryogenesis.

The essential role of imprinted genes for fetal/placental growth and tissue differentiation makes them primary candidates when searching for an explanation for the developmental abnormalities and medical problems which have been associated with ARTs. In light of the ethical and legal restrictions in human studies, the bovine oocyte and embryo model gains increasing importance. Here, we have characterized the bovine IGF2-H19 ICR which arguably is the most thoroughly studied imprinted domain in humans and mice. Different methylation abnormalities of this region have been associated with fetal growth retardation and overgrowth syndromes in humans [Cooper et al., 2005; Gicquel et al., 2005]. The parent-specific methylation and the presence of a highly conserved $\mathrm{CpG}$ island with CTCF-binding site provide strong evidence that the cloned amplicon, which lies -6.1 $\mathrm{kb}$ to $-5.7 \mathrm{~kb}$ of the H19 TSS, is part of the bovine intergenic IGF2-H19 ICR. The adjacent $-5.7 \mathrm{~kb}$ to $-3 \mathrm{~kb}$ segment contains additional CTCF-binding sites and less conserved $\mathrm{CpG}$ islands, which are also differentially methylated. We conclude that the bovine IGF2-H19 ICR extends over $3.1 \mathrm{~kb}$ from $-6.1 \mathrm{~kb}$ to $-3 \mathrm{~kb}$ upstream of the TSS. It is more similar to the $3.3-\mathrm{kb}$ human IGF2-H19 IC1, which lies $-5.3 \mathrm{~kb}$ to $-2 \mathrm{~kb}$ upstream of the H19 TTS [Frevel et al., 1999] than to the mouse IGF2-H19 DMD, which has been localized $-4 \mathrm{~kb}$ to $-2 \mathrm{~kb}$ upstream of the TSS [Tremblay et al., 1997]. In addition, sequence conservation of the IGF2-H19 ICR is higher between human and cow (54\%) than between human and mouse (51\%). Our results and the developed assays for fast quantitative methylation analysis of the bovine IGF2-H19 and other representative DMRs will facilitate experimental work on how in vitro manipulation of germ cells and embryos can influence genomic imprinting and development.

\section{Acknowledgement}

Supported by the German Research Foundation (FOR 1041). 


\section{References}

-Altschul SF, Gish W, Miller W, Myers EW, Lipman DJ: Basic local alignment search tool. J Mol Biol 215:403-410 (1990).

-Bao L, Zhou M, Cui Y: CTCFBSDB: a CTCFbinding site database for characterization of vertebrate genomic insulators. Nucleic Acids Res 36:83-87 (2008).

- Beaujean N, Hartshorne G, Cavilla J, Taylor JE, Gardner J, et al: Non-conservation of mammalian preimplantation methylation dynamics. Curr Biol 14:R266-R267 (2004).

- Bell AC, Felsenfeld G: Methylation of a CTCFdependent boundary controls imprinted expression of the Igf2 gene. Nature 405:482485 (2000).

-Bowdin S, Allen C, Kirby G, Brueton L, Afnan $M$, et al: A survey of assisted reproductive technology births and imprinting disorders. Hum Reprod 22:3237-3240 (2007)

-Brudno M, Do CB, Cooper GM, Kim MF, Davydov E, et al: LAGAN and Multi-LAGAN: efficient tools for large-scale multiple alignment of genomic DNA. Genome Res 13:721731 (2003).

- Cezar GG, Bartolomei MS, Forsberg EJ, First NL, Bishop MD, Eilertsen KJ: Genome-wide epigenetic alterations in cloned bovine fetuses. Biol Reprod 68:1009-1014 (2003).

- Cooper WN, Luharia A, Evans GA, Raza H, Haire AC, et al: Molecular subtypes and phenotypic expression of Beckwith-Wiedemann syndrome. Eur J Hum Genet 13:1025-1032 (2005).

Curchoe CL, Zhang S, Yang L, Page R, Tian XC: Hypomethylation trends in the intergenic region of the imprinted IGF2 and H19 genes in cloned cattle. Anim Reprod Sci 116:213225 (2009)

-Dean W, Santos F, Stojkovic M, Zakhartchenko $\mathrm{V}$, Walter J, et al: Conservation of methylation reprogramming in mammalian development: aberrant reprogramming in cloned embryos. Proc Natl Acad Sci USA 98:1373413738 (2001).

Doornbos ME, Maas SM, McDonnell J, Vermeiden JP, Hennekam RC: Infertility, assisted reproduction technologies and imprinting disturbances: a Dutch study. Hum Reprod 22:2476-2480 (2007).

-Edwards CA, Ferguson-Smith AC: Mechanisms regulating imprinted genes in clusters. Curr Opin Cell Biol 19:281-289 (2007).

- Engel N, Thorvaldsen JL, Bartolomei MS: CTCF binding sites promote transcription initiation and prevent DNA methylation on the maternal allele at the imprinted H19/Igf2 locus. Hum Mol Genet 15:2945-2954 (2006).

Ertzeid G, Storeng R: The impact of ovarian stimulation on implantation and fetal development in mice. Hum Reprod 16:221-225 (2001).

Farin PW, Piedrahita JA, Farin CE: Errors in development of fetuses and placentas from in vitro-produced bovine embryos. Theriogenology 65:178-191 (2006).
Fortier AL, Lopes FL, Darricarrere N, Martel J, Trasler JM: Superovulation alters the expression of imprinted genes in the midgestation mouse placenta. Hum Mol Genet 17:1653 1665 (2008).

Frevel MA, Sowerby SJ, Petersen GB, Reeve AE: Methylation sequencing analysis refines the region of hH19 epimutation in Wilms tumor. J Biol Chem 274:29331-29340 (1999).

- Gebert C, Wrenzycki C, Herrmann D, Gröger D, Reinhardt R, et al: The bovine IGF2 gene is differentially methylated in oocyte and sperm DNA. Genomics 88:222-229 (2006).

Gebert C, Wrenzycki C, Herrmann D, Gröger D, Thiel J, et al: DNA methylation in the IGF2 intragenic DMR is re-established in a sexspecific manner in bovine blastocysts after somatic cloning. Genomics 94:63-69 (2009).

- Gicquel C, Rossignol S, Cabrol S, Houang M, Steunou V, et al: Epimutation of the telomeric imprinting center region on chromosome 11 15 in Silver-Russell syndrome. Nat Genet 37:1003-1007 (2005).

- Gregg C, Zhang J, Weissbourd B, Luo S, Schroth GP, et al: High-resolution analysis of parentof-origin allelic expression in the mouse brain. Science 329:643-648 (2010).

Haaf T: Methylation dynamics in the early mammalian embryo: implications of genome reprogramming defects for development. Curr Top Microbiol Immunol 310:13-22 (2006).

- Hajkova P, Erhardt S, Lane N, Haaf T, El-Maarri $\mathrm{O}$, et al: Epigenetic reprogramming in mouse primordial germ cells. Mech Dev 117:15-23 (2002).

Hall T: Bioedit: a user-friendly biological sequence alignment editor and analysis program for windows 94/95/NT. Nucleic Acids Symp 41:95-98 (1999).

Halliday J, Oke K, Breheny S, Algar E, Amor DJ: Beckwith-Wiedemann syndrome and IVF: a case-control study. Am J Hum Genet 75: 526-528 (2004).

-Hansen M, Bower C, Milne E, de Klerk N, Kurinczuk JJ: Assisted reproductive technologies and the risk of birth defects - a systematic review. Hum Reprod 20:328-338 (2005).

Horsthemke B, Buiting K: Imprinting defects on human chromosome 15. Cytogenet Genome Res 113:292-299 (2006).

-Huang JM, Kim J: DNA methylation analysis of the mammalian PEG3 imprinted domain. Gene 442:18-25 (2009).

Ideraabdullah FY, Vigneau S, Bartolomei MS: Genomic imprinting mechanisms in mammals. Mutat Res 647:77-85 (2008).

Jirtle RL, Weidmann JR: Imprinted and more equal. Am Sci 95:143-149 (2007).

Kallen B, Finnstrom O, Nygren KG, Olausson PO: In vitro fertilization (IVF) in Sweden: risk for congenital malformations after different IVF methods. Birth Defects Res A Clin Mol Teratol 73:162-169 (2005).
Kelsey G: Genomic imprinting - roles and regulation in development. Endocr Dev 12:99112 (2007).

Khosla S, Dean W, Brown D, Reik W, Feil R: Culture of preimplantation mouse embryos affects fetal development and the expression of imprinted genes. Biol Reprod 64:918-926 (2001).

Lewis A, Mitsuya K, UmlaufD, Smith P, Dean W, et al: Imprinting on distal chromosome 7 in the placenta involves repressive histone methylation independent of DNA methylation. Nat Genet 36:1291-1295 (2004).

Li E: Chromatin modification and epigenetic reprogramming in mammalian development. Nat Rev Genet 3:662-673 (2002).

Li LC, Dahiya R: Methprimer: designing primers for methylation PCRs. Bioinformatics 18: 1427-1431 (2002).

Lidegaard O, Pinborg A, Andersen AN: Imprinting diseases and IVF: Danish national IVF cohort study. Hum Reprod 20:950-954 (2005).

Liu JH, Yin S, Xiong B, Hou Y, Chen DY, Sun QY: Aberrant DNA methylation imprints in aborted bovine clones. Mol Reprod Dev 75: 598-607 (2008)

- Lucifero D, Suzuki J, Bordignon V, Martel J, Vigneault C, et al: Bovine SNRPN methylation imprint in oocytes and day 17 in vitroproduced and somatic cell nuclear transfer embryos. Biol Reprod 75:531-538 (2006).

- Ludwig M, Katalinic A, Gross S, Sutcliffe A, Varon $\mathrm{R}$, Horsthemke B: Increased prevalence of imprinting defects in patients with Angelman syndrome born to subfertile couples. J Med Genet 42:289-291 (2005).

-Maher ER, Brueton LA, Bowdin SC, Luharia A, Cooper W, et al: Beckwith-Wiedemann syndrome and assisted reproduction technology (ART). J Med Genet 40:62-64 (2003).

- Mayer W, Niveleau A, Walter J, Fundele R, Haaf $\mathrm{T}$ : Demethylation of the zygotic paternal genome. Nature 403:501-502 (2000).

- Ménézo YJ, Hérubel F: Mouse and bovine models for human IVF. Reprod Biomed Online 4: 170-175 (2002).

Miozzo M, Simoni G: The role of imprinted genes in fetal growth. Biol Neonate 81:217228 (2002)

Niemann H, Carnwath JW, Herrmann D, Wieczorek G, Lemme E, et al: DNA methylation patterns reflect epigenetic reprogramming in bovine embryos. Cell Reprogram 12:3342 (2010).

Reik W, Walter J: Genomic imprinting: parental influence on the genome. Nat Rev Genet 2: 21-32 (2001)

- Reik W, Constância M, Fowden A, Anderson N, Dean W, et al: Regulation of supply and demand for maternal nutrients in mammals by imprinted genes. J Physiol 547:35-44 (2003). 
Schieve LA, Meikle SF, Ferre C, Peterson HB, Jeng G, Wilcox LS: Low and very low birth weight in infants conceived with use of assisted reproductive technology. N Engl J Med 346:731-737 (2002).

Shi W, Haaf T: Aberrant methylation patterns at the two-cell stage as an indicator of early developmental failure. Mol Reprod Dev 63: 329-334 (2002).

Suzuki J Jr, Therrien J, Filion F, Lefebvre R, Goff AK, Smith LC: In vitro culture and somatic cell nuclear transfer affect imprinting of SNRPN gene in pre- and post-implantation stages of development in cattle. BMC Dev Biol 9:9 (2009).
Takai D, Gonzales FA, Tsai YC, Thayer MJ, Jones PA: Large scale mapping of methylcytosines in CTCF-binding sites in the human H19 promoter and aberrant hypomethylation in human bladder cancer. Hum Mol Genet 10: 2619-2626 (2001).

Tost J, Dunker J, Gut IG: Analysis and quantification of multiple methylation variable positions in CpG islands by pyrosequencing. Biotechniques 35:152-156 (2003).

Tremblay KD, Duran KL, Bartolomei MS: A 5' 2-kilobase-pair region of the imprinted mouse $\mathrm{H} 19$ gene exhibits exclusive paternal methylation throughout development. Mol Cell Biol 17:4322-4329 (1997).

-Wrenzycki C, Herrmann D, Keskintepe L, Martins A Jr, Sirisathien S, et al: Effects of culture system and protein supplementation on mRNA expression in pre-implantation bovine embryos. Hum Reprod 16:893-901 (2001).
Wrenzycki C, Lucas-Hahn A, Herrmann D, Lemme E, Korsawe K, Niemann H: In vitro production and nuclear transfer affect dosage compensation of the X-linked gene transcripts G6PD, PGK, and Xist in preimplantation bovine embryos. Biol Reprod 66:127134 (2002).

Wrenzycki C, Herrmann D, Lucas-Hahn A, Gebert $\mathrm{C}$, Korsawe $\mathrm{K}$, et al: Epigenetic reprogramming throughout preimplantation development and consequences for assisted reproductive technologies. Birth Defects Res C Embryo Today 75:1-9 (2005).

Young LE, Fernandes K, McEvoy TG, Butterwith SC, Gutierrez CG, et al: Epigenetic change in IGF2R is associated with fetal overgrowth after sheep embryo culture. Nat Genet 27:153154 (2001). 